\title{
GANHO DE DESEMPENHO FOTOSSINTÉTICO PROMOVIDO PELO AUMENTO NA CONCENTRAÇÃO FOLIAR DE MAGNÉSIO EM ARROZ
}

\author{
Sandro Dan Tatagiba' \\ Anelisa de Figueiredo Peloso \\ Fabrício Ávila Rodrigues ${ }^{3}$
}

\begin{abstract}
Resumo: O objetivo deste estudo foi investigar o efeito do magnésio ( $\mathrm{Mg}$ ) sobre os parâmetros de trocas gasosas da fotossíntese [assimilação líquida de CO2 (A), condutância estomática (gs) e concentração interna de CO2 (Ci)], dos parâmetros de fluorescência da clorofila (Chl) a \{fluorescência mínima (FO), fluorescência máxima $(F m)$, rendimento quântico do fotossistema II (Fv/Fm), coeficiente de extinção fotoquímica (qp), rendimento da fotoquímica [Y(II)], rendimento de dissipação de energia regulado [Y(NPQ)] e o rendimento das perdas de dissipação não reguladas $[Y(N O)]\}$, bem como sobre as concentrações de pigmentos cloroplastídicos em plantas de arroz cultivadas em solução nutritiva contendo 0,5 ou 1,5 mM de Mg (-Mg ou +Mg nas plantas, respectivamente). As plantas com + Mg apresentaram aumento do desempenho fotossintético em relação as plantas com - Mg. O aumento do desempenho fotossintético promovido por + Mg esteve associado aos incrementos nos pigmentos cloroplastídicos, no aumento de $A$ e do rendimento quântico fotoquímico da fotossíntese, demonstrado por qp e $Y(I I)$.
\end{abstract}

Palavras-chave: Fluorescência de imagem da clorofila a; Fotossíntese; Oryza sativa; Trocas gasosas.

\footnotetext{
1 Departamento de Biologia Vegetal/Universidade Federal de Viçosa, Brasil. E-mail: sandrodantatagiba@yahoo.com.br.

2 Departamento de Engenharia Rural/Universidade Federal do Espírito Santo, Brasil. E-mail: anelisapeloso@hotmail.com.

${ }^{3}$ Departamento de Fitopatologia/Universidade Federal de Viçosa, Brasil. E-mail: fabricio@ufv.br.
} 